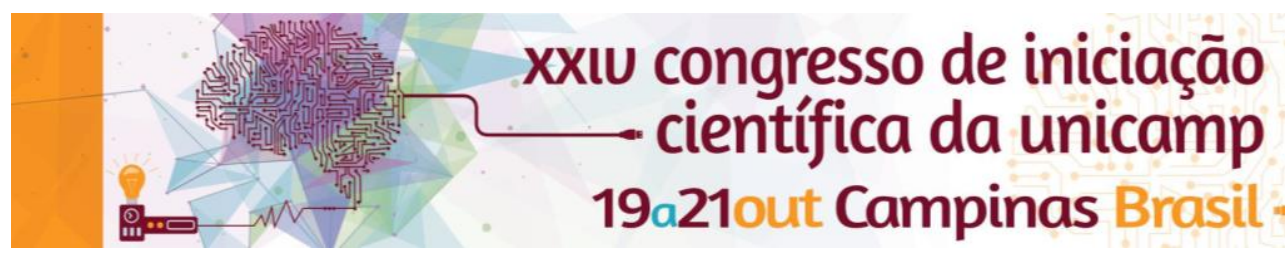

\title{
Adequação do consumo de gorduras saturadas em idosos do Municipio de Campinas.
}

\section{Erica Bronzi Durante*, Ligiana Pires Corona, Marilisa Berti de Azevedo Barros, Daniela de Assumpção.}

\section{Resumo}

O consumo excessivo de gorduras saturadas pode ser prejudicial à saúde, contribuindo para o desenvolvimento de várias doenças em idosos. A recomendação é que a ingestão diária de ácidos graxos saturados na dieta não ultrapasse $10 \%$ do valor energético total (VET). Objetivos: Avaliar a adequação do consumo de gorduras saturadas, segundo as condições sociodemográficas em idosos do município de Campinas. Métodos: Trata-se de estudo transversal, que avaliou o consumo de gorduras em 1.509 indivíduos de 60 anos e mais, participantes do Inquérito de Saúde no Município de Campinas (ISACAMP), realizado em 2008/2009. O consumo alimentar foi avaliado a partir do recordatório de 24 horas e as análises estatísticas foram realizadas levando-se em consideração os pesos amostrais para estimativas populacionais. O nível crítico utilizado foi $p<0,05$. Resultados e Discussões: A inadequação no consumo de gorduras saturadas, foi maior no sexo feminino, com maior escolaridade ( $\geq 8$ anos de estudo), e com maior renda ( $>2$ salários minímos).Conclusão: É importante avaliar a qualidade de distribuição de gorduras na dieta dos idosos, a fim de garantir um aporte adequado às necessidades deste grupo etário e contribuir para a prevenção de doenças crônicas, principalmente as doenças cardiovasculares.

Palavras-chave: idosos, gorduras, consumo

\section{Introdução}

O consumo excessivo de gorduras saturadas pode ser prejudicial à saúde, contribuindo para o desenvolvimento de várias doenças em idosos. A recomendação é que a ingestão diária de de ácidos graxos saturados na dieta não ultrapasse $10 \%$ do valor energético total (VET).

Por isso, o objetivo do estudo é avaliar a adequação do consumo de gorduras saturadas, segundo características sociodemográficas.

\section{Resultados e Discussão}

Trata-se de estudo transversal, que avaliou o consumo de gorduras em 1.509 indivíduos de 60 anos e mais, participantes do Inquérito de Saúde no Município de Campinas (ISACAMP), realizado em 2008/2009. O consumo alimentar foi avaliado a partir do recordatório de 24 horas e o nível crítico utilizado foi $p<0,05$.

O sexo feminino apresentou maior proporção de inadequação, quando comparado ao sexo masculino (50\% e $42,8 \%, p=0,002$ ). Em relação à escolaridade, idosos com 8 anos ou mais de estudo apresentaram maior proporção de inadequação, em relação aqueles menos escolarizados $(56,1 \%$ e $44,8 \% ; p<0,001)$, bem como os de renda mais alta - idosos com renda de 2 salários mínimos ou mais apresentam maior proporção de inadequação quando comparados aqueles que recebem entre 0,5 a 1 salários $(52,8 \%$ e $40,8 \% ; p<0,001)$.

Diante dos resultados, percebe-se que as pessoas com maior renda e escolaridade podem ter mais acesso para comprar alimentos de origem animal, como carnes e lácteos, e por isso podem ter consumo de saturadas excessivo.

Tabela 1. .\% Adequação do consume de gorduras saturadas, segundo as características sociodemográfica

\begin{tabular}{|c|c|c|c|}
\hline & \multicolumn{2}{|c|}{ Gordura Saturada } & \multirow[b]{2}{*}{ Valor $\mathbf{P}$} \\
\hline & Adequado & Inadequado & \\
\hline \multicolumn{4}{|l|}{ Sexo } \\
\hline Masculino & 57,2 & 42,8 & \multirow[t]{2}{*}{0,002} \\
\hline Feminino & 50,0 & 50,0 & \\
\hline \multicolumn{4}{|l|}{ Faixa Etária } \\
\hline 60 a 79 anos & 54,3 & 45,7 & \multirow[t]{3}{*}{0,59} \\
\hline 70 a 79 anos & 51,9 & 48,1 & \\
\hline$\geq 80$ anos & 50,8 & 49,2 & \\
\hline \multicolumn{4}{|l|}{ Escolaridade } \\
\hline Nunca foi à escola & 58,3 & 41,7 & \multirow[t]{3}{*}{0,001} \\
\hline 1 a 8 anos & 55,2 & 44,8 & \\
\hline 8 anos ou mais & 43,9 & 56,1 & \\
\hline \multicolumn{4}{|l|}{ Renda } \\
\hline$<0,5$ & 57,2 & 42,8 & \multirow[t]{3}{*}{0,01} \\
\hline$\geq 0,5-1$ & 59,2 & 40,8 & \\
\hline$>1<=2$ & 51,8 & 48,2 & \\
\hline$>2$ & 47,2 & 52,8 & \\
\hline \multicolumn{4}{|l|}{ Situação Conjugal } \\
\hline Com Companheiro & 54,8 & 45,2 & \multirow[t]{2}{*}{0,10} \\
\hline Sem Companheiro & 50,9 & 49,1 & \\
\hline
\end{tabular}

Nota: Adequado (consumo de até $10 \%$ do VET); Inadequando ( $\geq 10 \%$ do VET)

\section{Conclusões}

É importante avaliar a qualidade de distribuição de gorduras na dieta dos idosos, a fim de garantir um aporte adequado às necessidades deste grupo etário e contribuir para a prevenção de doenças crônicas, principalmente as doenças cardiovasculares.

\section{Agradecimentos}

Fundação de Amparo de Apoio à Pesquisa do Estado de São Paulo (FAPESP), Faculdade de Ciências Aplicadas (FCA).

FREITAS, Elizabete Viana de; PY, Ligia (ed.); CANÇADO, Flávio Aluizio Xavier; DOLL, Johannes; GORZZONI, Milton Luiz (Coaut. de). Tratado de geriatria e gerontologia.3. ed. Rio de Janeiro, RJ: Guanabara Koogan, 2011. 1741 p., il. ISBN 9788527719056 (enc.). 